\title{
Visitation restrictions: is it right and how do we support families in the NICU during COVID-19?
}

\author{
Peter D. Murray ${ }^{1} \cdot$ Jonathan R. Swanson $\mathbb{D}^{1}$
}

Received: 13 May 2020 / Revised: 27 July 2020 / Accepted: 3 August 2020 / Published online: 8 August 2020

(c) Springer Nature America, Inc. 2020

\begin{abstract}
Although the COVID-19 pandemic has largely not clinically affected infants in neonatal intensive care units around the globe, it has affected how care is provided. Most hospitals, including their NICUs, have significantly reduced parental and family visitation privileges. From an ethical perspective, this restriction of parental visitation in settings where infectious risk is difficult to understand. No matter what the right thing to do is, NICUs are currently having to support families of their patients via different mechanisms. In this perspective, we discuss ways NICUs can support parents and families when they are home and when they are in the NICU as well as provide infants the support needed when family members are not able to visit.
\end{abstract}

\section{Introduction}

To say the COVID-19 pandemic has upended the delivery of healthcare in the United States and the rest of the world would be a gross understatement. While the neonatal intensive care unit (NICU) has escaped, for the most part, the ramifications of having patients critically ill with COVID-19, the impact of this pandemic snaked its way through row upon row of incubators $[1,2]$. In addition to the potential for allocation or re-allocation of resources away from babies in the NICU, this pandemic forced healthcare providers and parents to face severe limitations to hospital visitation policies. That modern healthcare has evolved in the face of a pandemic is not surprising as, given the multitude of resources present for dealing with pandemic influenza, many in the public health sector and biomedical ethics have been preparing for such an occurrence [3, 4]. Importantly, while many resources developed in response to pandemic influenza or other natural disasters discuss care delivery to neonates in times of crisis, few, if any, discuss repercussions of limitations to visitation rights [5].

Jonathan R. Swanson

jswanson@virginia.edu

1 Department of Pediatrics, Division of Neonatology, University of Virginia Children's Hospital, Charlottesville, VA, USA
The notions of "quarantine" and "social distancing" are not new concepts. They, represent a means to a necessary end, lessening the impact of a pandemic. Accepting that parents are a vital part of the healthcare team providing care for the newborn, it follows that parents' rights to visit their baby should only be limited in extreme circumstances. Importantly, while often used interchangeably, quarantine and isolation are very different. Quarantine involves limited mobility of a person who is not, to their best knowledge, currently infected with the pathogen causing the pandemic. There is less ethical defense for quarantine when compared to the isolation of a person with confirmed infection or symptoms of infection. Of course, COVID-19 appears to be contagious in the asymptomatic carrier state, thus the appeal to widespread quarantining at home.

\section{Ethical and legal considerations}

At the heart of debate regarding quarantining are the limitations of two essential liberties we hold dear, mobility, and the freedom of assembly. Such limitations are justified in particular circumstances, one of which is a pandemic of an infectious agent. Hospital policies that limit visitation of patients, and by extension, limit mobility, are rooted in consequentialist ideals [6]. This means such limitations must have a positive impact on the greater constituency; lower rates of infection, for example. Public health policies 
are entrenched with utilitarianism, the maximization of good for the highest number.

Different from utilitarianism is libertarianism, based on John Stuart Mill's on Liberty. Mill expounded upon the harm principle, a principle that states, "the only purpose for which power can be rightfully exercised over any member of a civilized community against his will, is to prevent harm to another." [7] The current pandemic would constitute justification of limited liberties even under the basis of libertarianism.

The prevention of further communicable diseases may meet both libertarian and utilitarian criteria for limited visitation or complete closing of the NICU to visitors. This draconian limitation of parents at the bedside can be justified if there are no other, less intrusive means of preventing transmission of a pathogen. The Siracusa Principles, outlined in 1984 by the United Nations, coalesced the conditions necessary to legitimize restrictive public health measures in the setting of a pandemic [8]. Importantly, these principles stipulate that the Stateuse the least restrictive measures of interference and disruption to achieve the public health goal. This freedom from undue interference refers to, even in the setting of a pandemic, a person's right to the least amount of interference [9].

Limitations on a person's mobility are extreme but sometimes necessary. If wearing personal protective equipment (PPE) cannot stem the spread of a pathogen, complete exclusion from the NICU is warranted given quarantine and limitation of visitation are the only means of containment. However, with the proper application of PPE, COVID-19 can be contained, and transmission reduced [10]. However, the prospect of allowing asymptomatic carriers, who could be contagious, into the NICU is daunting [11]. A precedent for disallowing some visitors (siblings) already exists throughout the respiratory viral season. Importantly, such measures aimed at limiting visitors at the bedside in NICUs have been shown to decrease the acquisition and transmission of respiratory viruses [12].

For visitation policies and limitations to mobility, consider the following exercise. Two mothers present to two different hospitals in the same zip code. Both women are pregnant at 24 weeks' gestation and are from the same community with the same degree of community transmission. Their community is under a mandated stay at home order, and both followed this order as have their contacts. Neither woman shows signs of systemic illness associated with the current pandemic. One woman presents to a hospital that allows no visitors. The other woman presents to a hospital with limitations to visitation though one visitor is allowed in the NICU with proper PPE. Both babies are born and do well in the delivery room with similar survival statistics as based on the Neonatal Network's Extremely Preterm Birth Outcomes Tool [13]. To disallow one baby's parents to visit while the other baby's parents may visit is disingenuous because the decision is not based on facts particular to the case or the community, but instead on hospital protocol.

While many Americans approve of quarantine measures to stem the transmission of pandemic disease, it is unclear what percentage of those polled had babies in the NICU $[14,15]$. What to do about parents then? Should they be allowed to visit with proper PPE? If one unit allows parents to visit with proper PPE, but another unit across town does not allow any visitors under any circumstances, is this justified? If parents cannot visit given limitations to mobility, should they be subject to reciprocity?

Classically, reciprocity refers to the right of a person impacted by the State to receive basic necessities in the event of quarantine [9]. The State's provision of basic necessities lessens the impact of the limitation to mobility. While reciprocity assumes meeting the basic needs of the State's quarantined constituent, many reasonable people can think of no more basic need than that of a parent to be with their newborn. In the absence of the State's provision of means to achieve reciprocity, NICUs across the United States have had to be creative with how to allow parents feel a part of their baby's life to prevent theoretical consequences of limited visitation.

\section{Theoretical consequences of limited visitation}

Whatever the rubric used to justify limited visitation to the NICU, the reader must understand that such limitations do not come without repercussions. For example, a parent absent from the bedside of a neonate may have consequences we cannot anticipate, especially for their developmental potential. As neonatology moved toward more robust inclusion of the family at the bedside, their exclusion is held to a higher burden of proof of benefit from that exclusion.

Regardless of the method of inclusion, the family's role at the bedside, even in a virtual sense, is of paramount importance. Parental stress (particularly post-traumatic stress disorder following NICU admission) has been linked to poorer developmental outcomes in preterm infants [16]. Cessation of visitation all together, while not empirically studied in a pandemic, would undoubtedly add to the parental stress of NICU admission. This could further impact the eventual development of the neonate though time will tell how the current cohort of neonates, some of whom had visitation restricted, will develop.

What follows will be an explanation of attempts, thus far, to allow parents to feel a part of their neonate's care. This will not be exhaustive and, given the lack of previous 
pandemics to compare to, much of the presented information will be anecdotal or based on expert opinion.

\section{Solutions for supporting families}

\section{Supporting families at home}

As more and more hospitals limit and restrict visitation to hospitals including NICUs, opportunities to support parents, caregivers and other family members while they are home certainly increase. In the 21 st Century, much of this support could potentially be done through technology. Familycentered care in the NICU requires communication and collaboration between families and health care providers [17]. However, when visitation is limited or restricted, building that trust may be difficult. Alternative methods of communication which include a video component have been studied [18].

Web-based videoconferencing using FaceTime (Apple, Cupertino, CA) and Skype (Skype Technologies, Redmond, WA) and commercially available camera systems such as Angel Eye (AngelEye Health, Little Rock, AR) and NICView (Natus, San Carlos, CA) have demonstrated benefits [19-29]. In their integrative review, Epstein and colleagues found that all studies of video technology-based interventions demonstrated parental appreciation of being able to see their infant when they could not be in the NICU. Parents believed that being able to visualize their infant reduced stress and anxiety and relief that their child was doing well [26-28]. A minority of parents felt guilt at not being able to be with their infant when they viewed them on a camera [28]. Overall, Epstein and colleagues found videoconferencing "...to be helpful and meaningful to parents" across studies [18]. Real-time videoconferencing should be considered by NICUs who have limited visitation as a means for families to see their child as well as communicate with the healthcare team. Videoconferencing will also allow extended family members such as siblings and grandparents to interact with their new family member. For those NICUs with limited resources, health system information technology departments may have the ability to provide other options than those which require significant monetary investment. Smartphone applications may also be considered [30].

Families that are not able to visit, or those that have visitation restrictions, also miss out on interacting with peers. Peer-to-peer support for families in the NICU is important. Support groups have been found to help parents normalize their experiences, work through issues of guilt and coping mechanisms, and adapt to life in the NICU [31]. Hall et al. recommend offering peer support to NICU families as one of the primary components of familycentered care [32]. Most studies evaluating peer support in the NICU have looked at in-person programs moderated by former NICU parents. However, with visitation restrictions and recommendations for social distancing in the era of COVID-19, it is unlikely that these support programs can meet in or outside of the hospital. With that, families may look to internet support groups even more. Benefits to online support groups include the ability to access groups specific to their needs (i.e., congenital anomalies, genetic disorders) and on their own time [32]. In addition, parents can post anonymously, there may be decreased biases based on gender or socioeconomic status, and support can continue beyond hospitalization [32-35]. Of course, internet support groups can have drawbacks. Nonsupportive posts, misinformation, or unreliable data may be shared, especially if the group is not followed by experienced or knowledgeable moderators $[32,36]$. Some online support groups can be found in Table 1 and additional support groups sorted by country can be found at the European Foundation for the Care of Newborn Infants website. Additional strategies for families while away from their infant include journaling and tracking NICU milestones and developments [37].

\section{Supporting families in the NICU}

When parents are allowed to visit in the NICU, supporting them in the moment is imperative. Studies have shown that
Table 1 NICU parental/ caregiver online support groups.

\begin{tabular}{lll}
\hline Group & Internet address & Country \\
\hline Bliss & www.bliss.org.uk & United Kingdom \\
Canadian Premature Babies Foundation & www.cpbf-fbpc.org & Canada \\
European Foundation for the Care of Newborn Infants & www.efcni.org & n/a \\
Graham's Foundation & www.grahamsfoundation.org & United States \\
Hand to Hold & www.handtohold.org & United States \\
Leo's & www.leosneonatal.org & United Kingdom \\
Life with a Baby & www.lifewithababy.com & Canada \\
March of Dimes & www.marchofdimes.org & United States \\
NICU Parent Network & www.nicuparentnetwork.org & United States \\
\hline
\end{tabular}


Table 2 Recommendations for improving parental support in the NICU ${ }^{\mathrm{a}}$.

Staff education
Topics of education
- Normal Responses to Infant Hospitalization
- Mood and Anxiety Disorders in NICU Parents
- Family-centered Developmental Care
- Culturally Effective Care
- Normal Responses to Infant Hospitalization
- Self-care for Parents
Models of Communication Training
- Simulation Training
- Interactive Workshops
- Providing Increased \& More Sensitive Communication
- Listening Visits
Staff support
Personnel
- Psychologists
- Social Workers
- Pastoral Care/Chaplains
- Palliative Care
- NICU-specific Ethics Committee
Methods of Support
- Debriefing Sessions
- Bereavement Participation
- Physical Environment Changes
- Hospital Administration Support
Pats

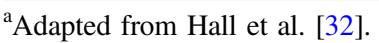

in general, parents do feel supported in the NICU from both nursing and medical providers [38]. However, there is consistent desire for more information on their child as well as emotional support [38-40]. In times of reduced visitation, how do we enhance psychosocial support of NICU parents? Hall et al. provide several recommendations that can be quickly implemented and/or augmented (Table 2) [41]. Ensuring that mental health professionals such as psychologists and social workers continue to work with families is imperative. Pastoral or religious care personnel can also supplement support while families are in the NICU. Palliative care teams and ethics committees may also benefit certain populations within the NICU and ensuring that these services are still provided is important.

For institutions that severely limited visitation of parents to the NICU, a central tenet of modern neonatology was unable to be performed by the parents. Kangaroo Care has been a part of neonatology since 1978 [42]. Countless neonates have benefitted from Kangaroo Care with benefits including; improved temperature regulation, improved sleep-wake cycles, and augmented growth [43]. To deny parents the experience to provide kangaroo care and neonates the demonstrated ability to reap its benefits seems imprudent, especially when, if available, PPE could mitigate unwanted effects of a viral agent. Other ways that families can impact the care when they are visiting include reading to their infants. Several studies have demonstrated improved parental bonding and decreased severity of postpartum depression after reading to their baby [44-46]. Parent talk has also been demonstrated to be the strongest predictor of preterm infant vocalizations at 32 and 36 weeks' gestation [47]. It was noted that infants were exposed to more conversational language when parents were present than when parents were absent [47].

\section{Supporting infants in the NICU}

The impact on reduced visitation does not simply affect the visitor, but also has profound impact on the patient as well. The neurobehavioral impact of parental visitation on infants is undeniable [48, 49]. So, in time of reduced visitation, the NICU team needs to ensure that care typically provided by parents does not stop. Talking in conversations to the infant, holding and interacting all can have significant impact over time. Music therapy has been shown to reduce infant respiratory rates and may have other physiological benefits [50]. Ensuring that therapy services such as occupational, speech, and physical therapists continue to help provide developmental support is imperative during this time.

In conclusion, although there is substantial evidence that would suggest parental visitation should not change in the NICU environment, we understand that hospital and infectious disease policies may supersede unit guidelines in the attempt to mitigate viral spread. If parental visitation is restricted, there are mechanisms that NICUs can utilize to ensure that families and infants continue to be supported both in the hospital and when they are away from the hospital.

\section{Compliance with ethical standards}

Conflict of interest The authors declare that they have no conflict of interest.

Publisher's note Springer Nature remains neutral with regard to jurisdictional claims in published maps and institutional affiliations.

\section{References}

1. Zeng L, Xia S, Yuan W, Yan K, Xiao F, Shao J, et al. Neonatal early-onset infection with SARS-CoV-2 in 33 neonates born to mothers with COVID-19 in Wuhan, China. JAMA Pediatr. 2020; 174:722-25.

2. Lavizzari A, Klingenberg C, Profit J, Zupancic JAF, Davis AS, Mosca $\mathrm{F}$, et al. International comparison of guidelines for managing neonates at the early phase of the SARS-CoV-2 pandemic. 
Pediatr Res. 2020. https://doi.org/10.1038/s41390-020-0976-5. [Epub ahead of print].

3. Jester BJ, Uyeki TM, Patel A, Koonin L, Jernigan DB. 100 years of medical countermeasures and pandemic influenza preparedness. Am J Public Health. 2018;108:1469-72.

4. Horby P. Improving preparedness for the next flu pandemic. Nat Microbiol. 2018;3:848-50.

5. Barfield WD, Krug SE. Committee on Fetus and Newborn, Disaster Preparedness Advisory Council. Disaster preparedness in neonatal intensive care units. Pediatrics. 2017;139:e20170507.

6. Wynia M. Ethics and public health emergencies: restrictions on liberty. Am J Bioeth. 2007;7:1-5.

7. John Stuart Mill. On Liberty. Oxford, England. Oxford University Press; 1859

8. Siracusa Principles on the Limitation and Derogation Provisions in the International Covenant on Civil and Political Rights, U.N. Doc E/CN.4/1985/4, Annex (1985).

9. Silva D, Smith M. Limiting rights and freedoms in the context of Ebola and other public health emergencies: how the principle of reciprocity can enrich the application of the Siracusa Principles. Health Hum Rights. 2015;17:E52-7.

10. Cook TM. Personal protective equipment during the coronavirus disease (COVID) 2019 pandemic - a narrative review. Anaesthesia. 2020;75:920-27.

11. Bai Y, Yao L, Wei T, Tian F, Jin DY, Chen L, et al. Presumed asymptomatic carrier transmission of COVID-19. JAMA. 2020; 323:1406-7.

12. Shul JE, Messina M, Hill-Ricciuti A, Maykowski P, Leone T, Sahni R, et al. Impact of respiratory viruses in the neonatal intensive care unit. J Perinatol. 2018;381:1556-65.

13. NICHD extremely preterm birth outcomes tool. https://www. nichd.nih.gov/research/supported/EPBO/use. Accessed 10 May 2020.

14. Blendon RJ, Koonin LM, Benson JM, Cetron MS, Pollard WE, Mitchell EW, et al. Public response to community mitigation measures for pandemic influenza. Emerg Infect Dis. 2008;14:778-86.

15. Murad Y. As Trump eyes restarting economy, nearly 3 in 4 voters support national quarantine. 2020. Morning Consult. https:// morningconsult.com/2020/03/25/coronavirus-national-quarantinetrump/. Accessed 10 May 2020.

16. Turpin H, Urben S, Ansermet F, Borghini A, Murray MM, Muller-Nix C. The interplay between prematurity, maternal stress and children's intelligence quotient at age 11: a longitudinal study. Sci Rep. 2019;9:450.

17. Committee on Hospital Care. Family-centered care and the pediatrician's role. Pediatrics. 2003;112:691-96.

18. Epstein EG, Arechiga J, Dancy M, Simon J, Wilson D, Alhusen JL. Integrative review of technology to support communication with parents of infants in the NICU. J Obstet Gynecol Neonatal Nurs. 2017;46:357-66.

19. Epstein E, Sherman J, Blackman A, Sinkin RA. Testing the feasibility of skype and facetime updates with parents in the neonatal intensive care unit. Am J Crit Care. 2015;24:290-96.

20. Globus O, Leibovitch L, Maayan-Metzger A, Schushan-Eisen I, Morag I, Mazkereth R, et al. The use of short message services (SMS) to provide medical updating to parents in the NICU. J Perinatol. 2016;36:739-43.

21. Gray JE, Safran C, Davis RB, Pompilio-Weitzner G, Stewart JE, Zaccagnini L, et al. Baby CareLink: using the internet and telemedicine to improve care for high-risk infants. Pediatrics. 2000; 106:1318-24.

22. Gund A, Sjoqvist BA, Wigert H, Hentz E, Lindecrantz K, Bry K. A randomized controlled study about the use of eHealth in the home health care of premature infants. BMC Med Inform Decis Mak. 2013;13:22.
23. Joshi A, Chyou PH, Tirmizi Z, Gross J. Web camera use in the neonatal intensive care unit: impact on nursing workflow. Clin Med Res. 2016;14:1-6.

24. Lindberg B, Axelsson K, Ohrling K. Experience with videoconferencing between a neonatal unit and the families' home from the perspective of certified paediatric nurses. J Telemed Telecare. 2009; $15: 275-80$.

25. Lindberg B, Axelsson K, Ohrling K. Taking care of their baby at home but with nursing staff as support: the use of videoconferencing in providing neonatal support to parents of preterm infants. J Neonatal Nurs. 2009;15:47-55.

26. Piecuch RE, Roth RS, Clyman RI, Sniderman SH, Riedel PA, Ballard RA. Videophone use improves maternal interest in transported infants. Crit Care Med. 1983;11:655-56.

27. Rhoads SJ, Green A, Gauss CH, Mitchell A, Pate B. Web camera use of mothers and fathers when viewing their hospitalized neonate. Adv Neonatal Care. 2015;15:440-46.

28. Rhoads SJ, Green A, Mitchell A, Lynch CE. Neuro-protective core measure 2: partnering with families-exploratory study on web-camera viewing of hospitalized infants and the effect on parental stress, anxiety, and bonding. Newborn Inform Nurs Rev. 2015;15:104-10.

29. Yeo C, Ho SK, Khong K, Lau Y. Virtual visitation in the neonatal intensive care: experience with the use of internet and telemedicine in a tertiary neonatal unit. Perm J. 2011;15:32-36.

30. Northwestern Now. New app allows NICU families to 'visit' baby during COVID-19 pandemic. https://news.northwestern.edu/ stories/2020/03/nicu-app-limited-visitation-covid-19/. Accessed 5 May 2020.

31. Dahan S, Bourque CJ, Reichherzer M, Prince J, Mantha G, Savaria M, et al. Peer-support groups for families in neonatology: why and how to get started? Acta Paediatr. 2020. https://doi.org/ 10.1111/apa.15312. [Epub ahead of print].

32. Hall SL, Ryan DJ, Beatty J, Grubbs L. Recommendations for peer-to-peer support for NICU parents. J Perinatol. 2015;35: S9-13.

33. Dunham P, Hurshman A, Litwin E, Gusella J, Ellsworth C, Dodd P. Computer-mediated social support: single young mothers as a model system. Am J Community Psychol. 1998;26:281-306.

34. McNamara D. Health-oriented telecommunication: a community resource. Nurs Manag. 1994;25:40-41.

35. Kiesler S, Siegel J, McGuire T. Social psychological aspects of computer mediated communication. Am Psychol. 1984;39: 1123-34.

36. Scharer K. Internet social support for parents: the state of the science. J Child Adolesc Psychiatr Nurs. 2005;18:26-35.

37. Carley A. Can journaling provide support for NICU families? J Spec Pediatr Nurs. 2012;17:254-57.

38. Franck LS, Axelin A. Differences in parents', nurses' and physicians' views of NICU parent support. Acta Paediatr. 2013; 102:590-96.

39. Mok E, Leung SF. Nurses as providers of support for mothers of premature infants. J Clin Nurs. 2006;15:726-34.

40. Tran C, Medhurst A, O'Connell B. Support needs of parents of sick and/or preterm infants admitted to a neonatal unit. Neonatal Paediatr Child Health Nurs. 2009;12:12-17.

41. Hall SL, Cross J, Selix NW, Patterson C, Segre L, Chuffo-Siewaert $\mathrm{R}$, et al. Recommendations for enhancing psychosocial support of NICU parents through staff education and support. J Perinatol. 2015;35:529-36.

42. Charpak N, Ruiz JG, Zupan J, et al. Kangaroo Mother Care: 25 years after. Acta Paediatr. 2005;94:514-22.

43. Campbell-Yeo ML, Disher TC, Benoit BL, et al. Understanding kangaroo care and its benefits to preterm infants. Pediatr Health Med Ther. 2015;6:15-32. 
44. Scala M, Seo S, Lee-Park J, McClure C, Scala M, Palafoutas JJ, et al. Effect of reading to preterm infants on measures of cardiorespiratory stability in the neonatal intensive care unit. J Perinatol. 2018;38:1536-41.

45. Levesque BM, Tran A, Levesque E, Shrestha H, Silva R, Adams $\mathrm{M}$, et al. Implementation of a pilot program of Reach Out and Read in the neonatal intensive care unit: a quality improvement initiative. J Perinatol. 2018;38:759-66.

46. UVAToday. "Story time: a novel solution for preemies, moms suffering from postpartum depression." 2019. https://news.virginia. edu/content/story-time-novel-solution-preemies-moms-sufferingpostpartum-depression. Accessed 12 May 2020.
47. Caskey M, Stephens B, Tucker R, Vohr B. Importance of parent talk on the development of preterm infant vocalizations. Pediatrics. 2011;128:910-16.

48. Reynolds LC, Duncan MM, Smith GC, Mathur A, Neil J, Inder T, et al. Parental presence and holding in the neonatal intensive care unit and associations with early neurobehavior. J Perinatol. 2013; 33:636-41.

49. Latva R, Lehtonen L, Salmelin RK, Tamminen T. Visiting less than every day: a marker for later behavioral problems in Finnish preterm infants. Arch Pediatr Adolesc Med. 2004;158:1153-57.

50. Bieleninik L, Ghetti C, Gold C. Music therapy for preterm infants and their parents: a meta-analysis. Pediatrics. 2016;138:e20160971. 